\title{
Séance ordinaire de la Chambre médicale Jeudi, 8 mai 2014, Palais des Congrès, Bienne
}

Ordre du jour provisoire

- Accueil, communications

- $\quad$ Rapports d'activité 2013

- Comptes annuels 2013

- Rapport de la Commission de gestion

- Approbation des comptes annuels 2013

- Octroi des décharges

- Exposé d'un intervenant invité

- Elections

- Président de l'ISFM *

- Vice-président de la Commission de déontologie de la FMH

- Organe de contrôle

- Confirmation des membres de l'Assemblée des délégués nommés par les organisations faittières

- Modifications des Statuts, du Règlement d'exécution et du Code de déontologie

- Augmentation du capital-actions de HIN

- Règlement d'indemnisation des séances et des frais pour organes et commissions de la FMH

- Elaboration des statistiques sur les soins de santé ambulatoires de la Confédération

- Initiative populaire «Pour une caisse-maladie publique»

- Révision TARMED: crédit supplémentaire pour des ressources en personnel liées à des projets

- Contributions à des organisations externes

- Information concernant la collaboration avec l'IPI

- Information concernant l'article constitutionnel «Soins médicaux de base»

- Information concernant le «Pilotage des admissions»

- Informations du Comité central, du Secrétariat général et des divisions

- Divers

\footnotetext{
* Election du Président de l'ISFM: le mandat du Dr Werner Bauer, président de l'Institut suisse pour la formation médicale postgraduée et continue (ISFM), expire au printemps 2014. La direction de l'ISFM s'est prononcée à l'unanimité pour sa réélection. Ce mandat dure deux ans et se terminera au printemps 2016 lors de l'élection générale des organes de la FMH.
} 